\title{
A randomized controlled clinical trial comparing small buccal dehiscence defects around dental implants treated with guided bone regeneration or left for spontaneous healing
}

Jung, Ronald E ; Herzog, Milan ; Wolleb, Karin ; Ramel, Christian F ; Thoma, Daniel S ; Hämmerle, Christoph H F

\begin{abstract}
PURPOSE The aim of the present randomized controlled clinical study was to test whether small bony dehiscence defects $(\leq 5 \mathrm{~mm})$ left to heal spontaneously result in the same clinical and radiological outcome as defects treated with guided bone regeneration (GBR). MATERIALS AND METHODS Twenty-two patients who received at least one implant with a small bony dehiscence defect were enrolled in the study. If the defect height was $\leq 5 \mathrm{~mm}$, the site was randomly assigned to either the spontaneous healing (SH) group or the GBR group. In the SH group, the defect was left without any treatment. In the GBR group, the defects around the implants were grafted with deproteinized bovine bone mineral (DBBM) and covered with a native collagen membrane. Clinical and radiographic measurements were performed 6 months after implant placement with a reentry surgery and at the time of crown insertion and the subsequent follow-up appointments at 3, 6, 12 and 18 months after loading. For statistical analyses, the mixed linear model was applied for the clinical and radiographic measurements observed around the implants. Simple comparisons of the location of the measurements in the two independent groups are performed with the Mann-Whitney U-test. In addition, the mixed model assumptions were checked. RESULTS The implant and crown survival rate 18 months after loading was $100 \%$, revealing no serious biologic or prosthetic complication. The mean changes of the buccal vertical bone height between implant placement and reentry surgery after 6 months revealed a small bone loss of $-0.17 \pm 1.79 \mathrm{~mm}$ (minimum $-4 \mathrm{~mm}$ and maximum 2.5 $\mathrm{mm}$ ) for the SH group and a bone gain of $1.79 \pm 2.24 \mathrm{~mm}$ (minimum of $-2.5 \mathrm{~mm}$ and maximum of $5 \mathrm{~mm}$ ) for the GBR group, respectively $(\mathrm{P}=0.017)$. Radiographic measurements demonstrated a slight bone loss of $-0.39 \pm 0.49$ $\mathrm{mm}$ for the SH group and a stable bone level of $0.02 \pm 0.48 \mathrm{~mm}$ for GBR group after 18 months. All peri-implant soft tissue parameters revealed healthy tissues with no difference between the two groups. CONCLUSION Small bony dehiscence defects left for spontaneous healing demonstrated high implant survival rates with healthy and stable soft tissues. However, they revealed more vertical bone loss at the buccal aspect 6 months after implant insertion and also more marginal bone loss between crown insertion and 18 months after loading compared to sites treated with GBR.
\end{abstract}

DOI: https://doi.org/10.1111/clr.12806

Posted at the Zurich Open Repository and Archive, University of Zurich

ZORA URL: https://doi.org/10.5167/uzh-126606

Journal Article

Accepted Version

Originally published at:

Jung, Ronald E; Herzog, Milan; Wolleb, Karin; Ramel, Christian F; Thoma, Daniel S; Hämmerle, Christoph H F (2017). A randomized controlled clinical trial comparing small buccal dehiscence defects around dental implants 
treated with guided bone regeneration or left for spontaneous healing. Clinical Oral Implants Research, 28(3):348354.

DOI: https://doi.org/10.1111/clr.12806 


\title{
A randomized controlled clinical trial comparing small buccal dehiscence defects around dental implants treated with guided bone regeneration or left for spontaneous healing
}

\author{
Ronald E. Jung ${ }^{a^{*}}$, Milan Herzog ${ }^{b^{*}}$, Karin Wolleb ${ }^{a}$, Christian F. Ramel ${ }^{c}$, \\ Daniel S. Thoma, Christoph H. F. Hämmerle ${ }^{a}$
}

a Clinic of Fixed and Removable Prosthodontics and Dental Material Science, University of Zurich, Plattenstrasse 11, 8032 Zurich, Switzerland

${ }^{b}$ Private practice, Affoltern a. A., Switzerland

${ }^{\mathrm{c}}$ Private practice, Zürich, Switzerland

* Equally contributed

Running head: Dehiscency defects treated with GBR or left for spontaneous healing

Key words: GBR, membranes, graft material, bone substitute, dental implant, RCT, healing

Address for correspondence: $\quad$ Prof. Dr. Ronald E. Jung; PhD

Clinic of Fixed and Removable Prosthodontics and Dental Material Science

Center of Dental Medicine, University of Zurich

Plattenstrasse 11

$\mathrm{CH}-8032$ Zurich, Switzerland

Phone: +41446343252

Fax: +4144634 4305

e-mail: ronald.jung@zzm.uzh.ch 


\section{Abstract}

Purpose: The aim of the present randomized controlled clinical study was to test whether small bony dehiscence defects $(\leq 5 \mathrm{~mm})$ left to heal spontaneously result in the same clinical and radiological outcome as defects treated with guided bone regeneration (GBR).

Materials and Methods: 22 patients who received at least one implant with a small bony dehiscence defect were enrolled in the study. If the defect height was $\leq 5 \mathrm{~mm}$ the site was randomly assigned to either the spontaneous healing (SH) group or the GBR group. In the SH group the defect was left without any treatment. In the GBR group the defects around the implants were grafted with deproteinized bovine bone mineral (DBBM) and covered with a native collagen membrane. Clinical and radiographic measurements were performed 6 months after implant placement with a reentry surgery and at the time of crown insertion and the subsequent follow-up appointments at 3,6,12 and 18 months after loading. For statistical analyses the mixed linear model was applied for the clinical and radiographic measurements observed around the implants. Simple comparisons of the location of the measurements in the two independent groups are performed with the Mann-Whitney test. In addition the mixed model assumptions were checked.

Results: The implant and crown survival rate 18 months after loading was $100 \%$, revealing no serious biologic or prosthetic complication. The mean changes of the buccal vertical bone height between implant placement and reentry surgery after 6 months revealed a small bone loss of $-0.17 \pm 1.79 \mathrm{~mm}$ (minimum $-4 \mathrm{~mm}$ and maximum $2.5 \mathrm{~mm}$ ) for the $\mathrm{SH}$ group and a bone gain of $1.79 \pm 2.24 \mathrm{~mm}$ (minimum of $-2.5 \mathrm{~mm}$ and maximum of $5 \mathrm{~mm})$ for the GBR group, respectively $(p=0.017)$. Radiographic 
measurements demonstrated a slight bone loss of $-0.39 \pm 0.49 \mathrm{~mm}$ for the SH group and a stable bone level of $0.02 \pm 0.48 \mathrm{~mm}$ for GBR group after 18 months. All periimplant soft tissue parameters revealed healthy tissues with no difference between the two groups.

Conclusion: Small bony dehiscence defects left for spontaneous healing demonstrated high implant survival rates with healthy and stable soft tissues. However, they revealed more vertical bone loss at the buccal aspect 6 months after implant insertion and also more marginal bone loss between crown insertion and 18 months after loading compared to sites treated with GBR. 


\section{Introduction}

In the early days of implant dentistry, the position of dental implants was mainly based on availability of native bone. The goal was for the implant to be surrounded by native bone, without creating a bone dehiscency. Recently, the concept of prosthetically driven implant placement has become widespread because it provides more favorable conditions for the prosthetic treatment. When implants are being placed in the prosthetically correct position, bone dehiscencies are more likely to occur. These defects can be successfully treated with guided bone regeneration (GBR) using membranes and bone substitution materials (Berglundh \& Lindhe 1997, Hammerle \& Karring 1998, Hammerle \& Lang 2001, Simion et al. 1997, Zitzmann et al. 1997).

However, the advantage of applying GBR to small dehiscency defect ( $\leq 5 \mathrm{~mm}$ ) in the posterior area has never been documented. Small dehiscency defects left to spontaneous healing have been investigated in relation to implant stability (Carmagnola et al. 1999, Palmer et al. 1994, Rasmusson et al. 1997). These clinical studies showed that small dehiscency defects did not have an effect on implant stability. However, the effect on the peri-implant mucosa was not evaluated. The disadvantage of spontaneous healing is that the corono-buccal aspect of the implant will be covered only by mucosa instead of newly formed bone and mucosa. This might lead to soft tissue recession and exposition of the rough surface of the implant. In patients with insufficient oral hygiene, the exposed rough surface will lead to plaque accumulation. The formation of biofilm could result in peri-implant mucositis (Pontoriero et al. 1994, Zitzmann et al. 2001) or eventually in peri-implantitis with bone loss. 
These negative consequences of the exposed rough surfaces can be avoided by applying GBR to the small dehiscency defects. However, the application of GBR has also negative side effects: increased treatment and healing time, increased treatment cost and a higher patient morbidity, e.g. swelling or the risk for infection. In consideration of all these factors, it is essential that in small dehiscence defects GBR is only applied when it is absolutely necessary for the long-term stability and health of the peri-implant tissues.

The aim of this study was to test whether small bony dehiscence defects $(\leq 5 \mathrm{~mm}$ ) left to heal spontaneously result in the same clinical and radiological outcome as small dehiscence defects treated with GBR using deproteinized bovine bone mineral (DBBM) and collagen membrane.

\section{Material and Methods}

The present study is a prospective, single-center, randomized, controlled clinical investigation. Patient recruitment, treatment and follow-ups were performed in a private practice environment (M.H) The clinical study protocol and all procedures and materials were approved by the local ethical committee of the Canton of Zurich (KEK) before the start of the study (Ref.Nr.: StV08/08). Informed consent was

obtained from all patients before any study procedures were performed. The study was monitored by an independent study monitor to ensure consistency and accuracy. 


\section{Patients}

The study recruited 22 male or female patients in need of implant treatment in the posterior mandible or maxilla with an expected osseous defect of maximum $5 \mathrm{~mm}$ in vertical dimension. In addition, the local hard- and soft-tissue architecture should allow inserting implants in a prosthetically driven position.

All patients were in good general health and underwent comprehensive dental care. 18 patients were non-smokers, 2 smoked less than 10 cigarettes/day and 2 smoked between 10 and 20 cigarettes/day.

Enrolled patients complied with all of the inclusion and exclusion criteria. Two of the inclusion criteria, such as primary stability of the dental implant and osseous dehiscence defects $\leq 5 \mathrm{~mm}$ in vertical dimension could only be evaluated at the day of surgery. If two or more sites were still available fulfilling the defect criterion, one was randomly selected for further statistical analysis. The selected site was assigned to a treatment according to the randomization envelope.

In the event that a patient was found to be ineligible for the study at the time of surgery, an alternative treatment following good clinical standards was offered to the patient.

\section{Surgical procedure}

The implant placement was performed either as a delayed (between 6 weeks and 6 months after tooth extraction) or a late procedure (more than 6 months after tooth extraction). Before surgery the patients received antibiotics $(2 \times 750 \mathrm{mg}$ Clamoxyl®; GlaxoSmithKline AG, Münchenbuchsee, Switzerland) and analgesics/antiphlogistics (500 mg Mefenacid®; Streuli Pharma AG, Uznach, Switzerland). Surgery was performed under local anesthetic. The incision was placed at the mid-crest, with 
releasing incisions if necessary, and a mucoperiosteal flap was raised. The implant site was prepared according to current standard of the Camlog System and a CAMLOG® SCREW-LINE implant (Camlog BiotechnologiesAG, Basel, Switzerland) was inserted.

Immediately after implantation, initial implant stability was assessed by hand testing. If any implant lacked primary stability at this assessment, the patient was excluded from further participation in the study.

The osseous defect of eligible sites was measured after implant placement with the help of a calibrated periodontal probe (Fig 1). If the defect height was more than 5 $\mathrm{mm}$ or had no defect, the patient was excluded from the study.

\section{Measurement of defect size}

- A: Vertical defect height $(\mathrm{mm})$ measured from the implant shoulder to the first bone-to-implant contact (BIC) (Fig. 1a).

- B: Infrabony defect height $(\mathrm{mm})$ measured from the bone crest to the first BIC (Fig. 1a).

- C: Defect width $(\mathrm{mm})$ measured from the mesial to the distal bone crests (Fig. 1b).

- D: Defect depth $(\mathrm{mm})$ measured from the bone crest to the implant surface in a direction perpendicular to the long axis of the implant (Fig. 1a).

\section{Randomization}

If the defect height was $\leq 5 \mathrm{~mm}$ the site was assigned to a treatment according to the randomization envelope: 
- Spontaneous healing (SH) group: The osseous defect was left without any treatment for spontaneous healing. The exposed implant serves was left untreated.

- Guided bone regeneration (GBR) group: Osseous defects around the implants were grafted with a deproteinized bovine bone mineral (DBBM) (BioOss ${ }^{\circledR}$ Spongiosa Granules, particle size 0.25 - $1.0 \mathrm{~mm}$; Geistlich Pharma AG, Wolhusen, Switzerland). The defect was filled with the bone substitute without being overfilled. Subsequently a collagen membrane of porcine origin was used (BioGide membrane, Geistlich Pharma AG, Wolhusen, Switzerland) to cover the grafting materials and the implant extending to palatal or lingual part of the alveolar ridge.

Since healing was attempted with the implants in a submerged position, the implants were covered with the mucosa. Periosteal releasing incisions were used to allow tension-free adaptation of the flap. The patients were instructed to rinse twice daily with an aqueous solution of $0.2 \%$ chlorhexidine and to continue the antibiotic

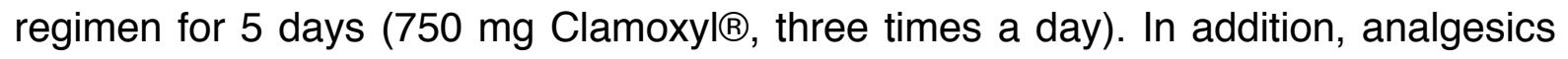
(500 mg Mefenacid®) were prescribed for the next 2 days according to individual needs. Patients were also instructed to refrain from mechanical plaque removal in the area of implantation for 1 week.

Suture removal was performed 1 week after surgery and another control appointment was scheduled 2 weeks postoperatively. 


\section{Reentry procedure}

Six months later, a re-entry surgery was performed to assess the results of the spontaneous healing or the surgical therapy. Mucoperiosteal flaps were reflected to allow for exact evaluation. The same clinical measurements assessed at baseline were again recorded (Fig. 1a to 1b) (primary parameter). Cover screws were replaced by healing abutments. Subsequently, the flaps were adjusted to fit around the neck of the healing abutment and sutured. One week later, the sutures were removed.

\section{Prosthetic reconstruction}

After the re-entry procedure 6 months following implant placement, the soft tissues were allowed to heal for at least 1 week before impression taking. Thereafter, the single crowns (or a fixed partial denture in one case) were incorporated, either screw-retained or cemented.

\section{Follow-up examinations}

All patients were enrolled in a maintenance care program during the entire study period of 18 months within a private practice environment. Clinical and radiographic assessments were performed at 3, 6, 12 and 18 months after insertion of the crowns.

\section{Clinical measurements}

At each time point the following parameters were examined at the enrolled implant during the clinical examination:

1. Implant survival 
2. Plaque index (PI) (Silness and Löe, 1964 (Silness \& Loe 1964)). For each of the 4 surfaces of the implants a score of 0 to 3 is given that matches the severity. 3. Probing pocket depths (PPD) were performed at six sites (mesio-buccal, midbuccal, disto-buccal, disto-lingual, mid-lingual, mesio-lingual) of each implant and recorded to the nearest millimeter with the periodontal probe UNC-15 using a force of 0.2-0.3 N (examiner M.H. was calibrated in advance).

4. Sulcus bleeding index (Muhlemann \& Son 1971) for each of the 4 surfaces of the implants

5. Mucosa level (distance between mucosa margin and rough/smooth border of the implant). Negative values $=$ the mucosa margin is apical to the rough/smooth border (6 sites per implant).

\section{Radiographic measurements}

For the evaluation of the marginal bone level, intraoral radiographs were taken using the long-cone paralleling technique with the central beam directed to the alveolar crest (Hawe x-ray film holder, Kerrhawe SA, Bioggio, Switzerland). The images were digitalized with a scanner (Epson Perfection V700 Pro Scanner) in a resolution of 1200 dpi.

The marginal bone level (MBL), i.e. the distance between the implant shoulder and the first visible bone-to-implant contact, was measured at the mesial and distal aspect with a 10-15x magnification (Buser et al. 1991, Weber et al. 1992) using an image analysis program (Image J, Version 1.44, U.S. National Institutes of Health, Bethesda, Maryland, USA). In order to adjust each radiograph for distortion they have been calibrated by a reference structure, which was the well-known implant diameter. 


\section{Statistical analysis}

The statistical analyses were performed applying SAS V 9.4 (SAS Institute Inc. Cary, North Carolina with Proc mixed).

For the description of the data, means, minimum and maximum, standard deviations (SDs) and medians were derived for quantitative variables, and percentages for qualitative categorical variables. The statistical independent unit is the patient. Because of several measurements within a patient and repeated measurements in time, the mixed linear model was applied for the clinical and radiographic measurements observed around the implants. This model takes into account these dependencies by using patient as random. As explanatory factor we used treatment and time as well as their interaction.

Since only four patients needed more than one implant, we selected at random one of the implants placed in a patient with more than one implant. With this slightly reduced data set we compared the two treatments using several continuous effect size measurements at surgery and at re-entry as well their difference with the Mann Whitney test. Also we derived the exact 95\% confidence intervals for the interesting results to estimate the true population location difference between the two treatments. 


\section{Results}

\section{Patients}

22 patients with a total of 28 implants were enrolled and included in the trial. Twelve patients with 15 implants were randomized to the spontaneous healing group (SH) and 10 patients with 13 implants to the guided bone regeneration group (GBR). The mean age was 56 years (range 40-74 years) in the SH group and also 56 years (range 35-75 years) in the GBR group. In the SH group there were 4 male and 8 female patients and in the GBR group there were 6 male and 4 female patients. The vast majority of the patients were non-smokers $(75 \%$ in the $\mathrm{SH}$ group and $90 \%$ in the GBR group).

\section{Surgical procedure and reentry}

Implant location and characteristics

The implant locations are displayed in table 1. The majority of the implants were placed at the position of teeth number 36 or 46 (FDI classification).

All types of implant lengths ranging from 9 to $13 \mathrm{~mm}$ and implant diameters ranging from 3.8 up to $5 \mathrm{~mm}$ have been inserted according to the local anatomic and prosthetic requirements.

\section{Clinical observations at implant installation}

All implants obtained primary stability after insertion. Both treatment groups were homogeneous with regard to the baseline values of the quantitative variables measured. The mean vertical defect height (A in Fig. 1a) at surgery was $3.25 \pm 1.18$ $\mathrm{mm}$ for the $\mathrm{SH}$ group and $3.64 \pm 1.37 \mathrm{~mm}$ for the GBR group without any statistical significance difference. No violation of any anatomic structure occurred. 
Healing period, soft tissue complications

During the submucosal healing period of 6 months no evidence of serious local or systemic adverse effects was observed in any of the groups.

In the spontaneous healing group, 2 implant sites revealed local infections after 3.5 weeks and 3 months, respectively. Both were treated by local disinfection (rinsing with $0.2 \%$ chlorhexidine) and completely recovered after 3 weeks. An additional implant in $\mathrm{SH}$ group revealed a partial exposure of the cover screw, which remained open until reentry surgery. At re-entry, a radiolucency and infection were noticed at an implant in the position 46. Three weeks later at impression/abutment placement exudation occurred at the sulcus and peri-implantitis was noticed. Rinsing with $\mathrm{CHX}$ was prescribed (3 weeks). At definitive prosthesis placement, no clinical signs of infection were noted, but a peri-implant radiolucency was still present.

In the GBR group, 2 implant sites showed a local exposure of the collagen membrane after 1 and 2 weeks, which was also treated by local application of $\mathrm{CHX}$. Both recovered and demonstrated intact soft tissue coverage. One implant site revealed a local infection after 1 week and another implant cover screw got partially exposed after 12 weeks. All complications recovered except the one with the exposed cover screw that remained exposed until reentry surgery after 6 months.

Bone measurements at re-entry

After a healing period of 6 months, a re-entry operation was performed for abutment connection and to measure the residual defects. At this time point, all implants were stable revealing an implant survival rate of $100 \%$. 
The measurements of the bone defects according to Fig $1 \mathrm{a}$ and $1 \mathrm{~b}$ are displayed in table 2. In regards to the remaining defect height (parameter A in Fig 1a), the spontaneous healing group revealed 5 out of 12 sites $(41.66 \%)$ with a vertical bone loss between implant insertion and the reentry procedure 6 months later. Three sites remained stable (25\%). Another 4 sites demonstrated a spontaneous bone gain (33.33\%). The mean difference in vertical bone height between the implant insertion and the reentry was $-0.17 \pm 1.79 \mathrm{~mm}$ (minimum $-4 \mathrm{~mm}$ and maximum $2.5 \mathrm{~mm}$ ) demonstrating a slight overall bone resorption (Table 2)

In the GBR group, 2 out of $10(20 \%)$ implants demonstrated a vertical bone loss 6 months after implant insertion. All other implants $(80 \%)$ showed bone regeneration with a reduced defect height at the reentry surgery. The mean overall vertical bone gain was $1.79 \pm 2.24 \mathrm{~mm}$ with a minimum of $-2.5 \mathrm{~mm}$ and a maximum of $5 \mathrm{~mm}$ (Table 2). This difference in vertical bone height between implant insertion and the reentry procedure 6 months later was statistically significantly different between $\mathrm{SH}$ and GBR group ( $p=0.017$, Mann Whitney test) favoring the GBR group. Regarding change in infrabony defect height (B), defect depth (D) and defect width (C), no statistically significant differences between the two groups were observed.

\section{Prosthetic reconstruction}

A total of 24 single crown reconstructions and 2 bridges were delivered to the patients. $57.1 \%$ of all the reconstructions were screw-retained and $42.9 \%$ cemented. All reconstructions were porcelain fused to metal reconstruction (PFM) except one single crown, which was a gold crown. 


\section{Follow-up examinations}

\section{Implant and crown survival}

The implant and crown survival rate after 18 months was 100\%, revealing no serious biologic or prosthetic complication. In the $\mathrm{SH}$ group, 2 ceramic chippings occurred in two patients 6 and 12 months after loading. Both could be polished with no further treatment.

In the GBR group one cemented crown became loose 1 month after cementation and could be recemented again. In another patient with a screw-retained single crown, a screw loosening took place 18 months after prosthetic insertion.

Probing pocket depth (PPD), sulcus bleeding index (SBI), plaque index (PI)

All periimplant measurements including $\mathrm{PPD}, \mathrm{SBI}$ and $\mathrm{PI}$ performed at the time of delivering the prosthetic reconstruction and at 3, 6, 12 and 18 months demonstrated healthy periimplant tissues with generally no statistical significant differences between the $\mathrm{SH}$ and the GBR group (Fig 2-4). The only periimplant parameter revealing a statistical significant difference $(p=0.030)$ between the test und control sites was the probing pocket depths mesio-orally.

\section{Mucosa level}

After 18 months, the mean marginal mucosa level in the spontaneous healing group was located $3.33 \pm 1.09 \mathrm{~mm}$ above the rough/smooth border of the implant. In the GBR group the mucosa was located $3.07 \pm 1.43 \mathrm{~mm}$ above the rough/smooth border of the implant revealing no statistical significant differences between the two groups (Fig. 5). In addition, the mucosal level revealed a slight overall gain from reentry to 
the 18 months follow-up without any statistical significant difference between the spontaneous group and the GBR group.

\section{Radiographic measurements}

The radiographic evaluation demonstrated that all implants were radiographically integrated indicated by a direct contact between the bone and the implant. The mean change in vertical bone level since crown insertion at the mesial and the distal site of the implants revealed a slight bone loss of $-0.39 \pm 0.49 \mathrm{~mm}$ for the $\mathrm{SH}$ group and a stable bone level of $0.02 \pm 0.48 \mathrm{~mm}$ for GBR group after 18 months.

\section{Discussion}

The present randomized controlled clinical study demonstrated high implant and crown survival rates 18 months after crown insertion. All periimplant soft tissue parameters revealed healthy tissues, with no difference between sites, which were left for spontaneous healing versus sites that were treated with GBR procedures. With respect to the bone level, the spontaneous healing group demonstrated statistically significant more vertical bone loss at the buccal aspect 6 months after implant insertion and slightly more marginal bone loss between crown insertion and the 18 months follow-up appointment.

In the present RCT a high survival rate of the implants of $100 \%$ could be found after a follow-up period of 18 months. This result was independent of whether or not a buccally exposed implant surface was left for spontaneous healing or was treated by means of GBR procedures. The implant survival rate in the present study is in agreement or slightly higher compared to a previously published systematic review 
revealing an implant survival rate of $97.2 \%$ after 5 years (Jung et al. 2012). However, it has to be emphasized that the present observation period is rather short and further assessments of the study population are required.

The mean vertical bone gain of the present study for the GBR group of $1.79 \pm 2.24$ $\mathrm{mm}$ can be considered low compared to other studies indicating bone gains of 5.63 $\mathrm{mm}$ using the same grafting materials as in the present study (Jung et al. 2009). This might be explained by the fact that the mean defect height at implant insertion was only $3.64 \pm 1.37 \mathrm{~mm}$. Since the implant had a machined neck of $1.4 \mathrm{~mm}$ height which was included in the defect measurements, the mean defect height was only about 2.2 $\mathrm{mm}$ from the smooth/rough border. The present study revealed that in the GBR group, in 2 out of 10 sites a vertical bone loss took place between implant insertion and reentry. These two sites revealed the smallest defects ( 1.5 to $2 \mathrm{~mm}$ ).

The question that is raised by the present study is whether or not in small bony dehiscence defects around implants a GBR procedure is necessary or not. This question has a high impact in clinical practice. Based on the limited number of patients it seems that the implant survival and the soft tissue stability was not influenced if a GBR procedure was performed or not on defects no bigger than $5 \mathrm{~mm}$ of exposed structured implant surface. In a previous retrospective clinical trial on immediate implants the dimension of the buccal bone and the mucosa was assessed using cone beam computed tomography after an observation period of 7 years (Benic et al. 2012). It was demonstrated that $30 \%$ of the implants revealed no radiographically detectable buccal bone at the 7-year control. Nevertheless, these implants revealed healthy soft tissue conditions with a mucosa level located only 1 $\mathrm{mm}$ more apically than at implants with intact buccal bone. Based on the present 
study and this clinical trial it might be speculated that stable soft tissue do not necessarily need a completely covered implant surface.

Within the limitation of the present study, where only a small group of 22 patients were treated, the results have to be interpreted with caution and the study might be considered a pilot study. Further limitations are related to the fact that only premolars and molars were included and that no individual bite blocks for the Rx holder have been used. In addition, it was difficult to judge the exact amount of mineralized tissue at the time of the reentry surgery due to the fact that there was no histological assessment. For the careful evaluation of the bone and soft tissue more long-term studies with larger population have to be designed. The positive effect of the periimplant soft tissue stability over the 18 months period could be reduced after a longer loading time.

\section{Conclusion}

It can be concluded that small bony dehiscence defects that were left for spontaneous healing demonstrated high implant survival rates with healthy and stable soft tissues. However, they revealed more vertical bone loss at the buccal aspect within the first 6 months after implant insertion. Within the limits of the present study it seems that GBR procedures improve the stability of the buccal bone of implants with buccal bony dehiscence defects. 


\section{Acknowledgements}

The authors express their special thanks to Prof. Dr. Jürg Hüsler, University of Bern, Switzerland for the statistical analysis of the present RCT. This study was supported with implant materials by a research grant of the CAMLOG Foundation (CF40806), Switzerland. 


\section{Figures and Tables: Legend}

Figure 1a,b: Defect dimensions measured at the time of implant placement and after reentry. A: Vertical defect height from implant shoulder to first BIC; B: Infrabony defect height C: Defect width from width from mesial to distal bone crests; D: Defect depth from bone crest to implant surface

Figure 2: Probing depth: Mean over all measurement sites (mean per implant)

Figure 3: Sulcus bleeding index: Mean over all measurement sites (mean per implant)

Figure 4: Plaque index: Mean over all measurement sites (mean per implant)

Figure 5: Mucosa level: Mean over all measurement sites (mean per implant)

Figure 6: Treatment example from the guided bone regeneration group

6a) initial bone defect at implant placement in position 26

6b) bone augmentation with DBBM

6c) clinical findings at re-entry 6 months after implant placement

6d) clinical findings at 18 months follow-up

6e) Radiograph at 18 months follow-up

Figure 7: Treatment example from the spontaneous healing group

7 a initial bone defect at implant placement in position 36

$7 \mathrm{~b}$ clinical findings at re-entry 6 months after implant placement

$7 \mathrm{c}$ clinical findings at 18 months follow-up

7 e Radiograph at 18 months follow-up 
Table 1: Distribution oft he implant positions (FDI classification)

Table 2: Bone changes from implant insertion to the reentry after 6 months (A_Diff, B_Diff, C_Diff, D_Diff; negative value = bone loss; positive value = bone gain), one implant selected per patient 


\section{References}

1. Benic, G. I., Mokti, M., Chen, C. J., Weber, H. P., Hammerle, C. H. \& Gallucci, G. O. (2012) Dimensions of buccal bone and mucosa at immediately placed implants after 7 years: A clinical and cone beam computed tomography study. Clinical Oral Implants Research 23: 560-566.

2. Berglundh, T. \& Lindhe, J. (1997) Healing around implants placed in bone defects treated with bio-oss. An experimental study in the dog. Clinical Oral Implants Research 8: 117-124.

3. Buser, D., Weber, H. P., Bragger, U. \& Balsiger, C. (1991) Tissue integration of one-stage iti implants: 3-year results of a longitudinal study with hollow-cylinder and hollow-screw implants. International Journal of Oral and Maxillofacial Implants 6: 405-412.

4. Carmagnola, D., Araujo, M., Berglundh, T., Albrektsson, T. \& Lindhe, J. (1999) Bone tissue reaction around implants placed in a compromised jaw. Journal of Clinical Periodontology 26: 629-635.

5. Hammerle, C. H. \& Karring, T. (1998) Guided bone regeneration at oral implant sites. Periodontology 2000 17: 151-175.

6. Hammerle, C. H. \& Lang, N. P. (2001) Single stage surgery combining transmucosal implant placement with guided bone regeneration and bioresorbable materials. Clinical Oral Implants Research 12: 9-18.

7. Jung, R. E., Halg, G. A., Thoma, D. S. \& Hammerle, C. H. (2009) A randomized, controlled clinical trial to evaluate a new membrane for guided bone regeneration around dental implants. Clinical Oral Implants Research 20: 162-168.

8. Jung, R. E., Zembic, A., Pjetursson, B. E., Zwahlen, M. \& Thoma, D. S. (2012) Systematic review of the survival rate and the incidence of biological, technical, and aesthetic complications of single crowns on implants reported in longitudinal studies with a mean follow-up of 5 years. Clinical Oral Implants Research 23 Suppl 6: 2-21.

9. Muhlemann, H. R. \& Son, S. (1971) Gingival sulcus bleeding--a leading symptom in initial gingivitis. Helvetica Odontologica Acta 15: 107-113.

10. Palmer, R. M., Floyd, P. D., Palmer, P. J., Smith, B. J., Johansson, C. B. \& Albrektsson, T. (1994) Healing of implant dehiscence defects with and without expanded polytetrafluoroethylene membranes: A controlled clinical and histological study. Clinical Oral Implants Research 5: 98-104.

11. Pontoriero, R., Tonelli, M. P., Carnevale, G., Mombelli, A., Nyman, S. R. \& Lang, N. P. (1994) Experimentally induced peri-implant mucositis. A clinical study in humans. Clinical Oral Implants Research 5: 254-259.

12. Rasmusson, L., Meredith, N. \& Sennerby, L. (1997) Measurements of stability changes of titanium implants with exposed threads subjected to barrier membrane induced bone augmentation. An experimental study in the rabbit tibia. Clinical Oral Implants Research 8: 316-322.

13. Silness, J. \& Loe, H. (1964) Periodontal disease in pregnancy. li. Correlation between oral hygiene and periodontal condtion. Acta Odontologica Scandinavica 22: 121-135.

14. Simion, M., Misitano, U., Gionso, L. \& Salvato, A. (1997) Treatment of dehiscences and fenestrations around dental implants using resorbable and 
nonresorbable membranes associated with bone autografts: A comparative clinical study. International Journal of Oral and Maxillofacial Implants 12: 159-167.

15. Weber, H. P., Buser, D., Fiorellini, J. P. \& Williams, R. C. (1992) Radiographic evaluation of crestal bone levels adjacent to nonsubmerged titanium implants. Clinical Oral Implants Research 3: 181-188.

16. Zitzmann, N. U., Berglundh, T., Marinello, C. P. \& Lindhe, J. (2001) Experimental peri-implant mucositis in man. Journal of Clinical Periodontology 28: 517-523.

17. Zitzmann, N. U., Naef, R. \& Scharer, P. (1997) Resorbable versus nonresorbable membranes in combination with bio-oss for guided bone regeneration. International Journal of Oral and Maxillofacial Implants 12: 844-852. 
Fig $1 a$

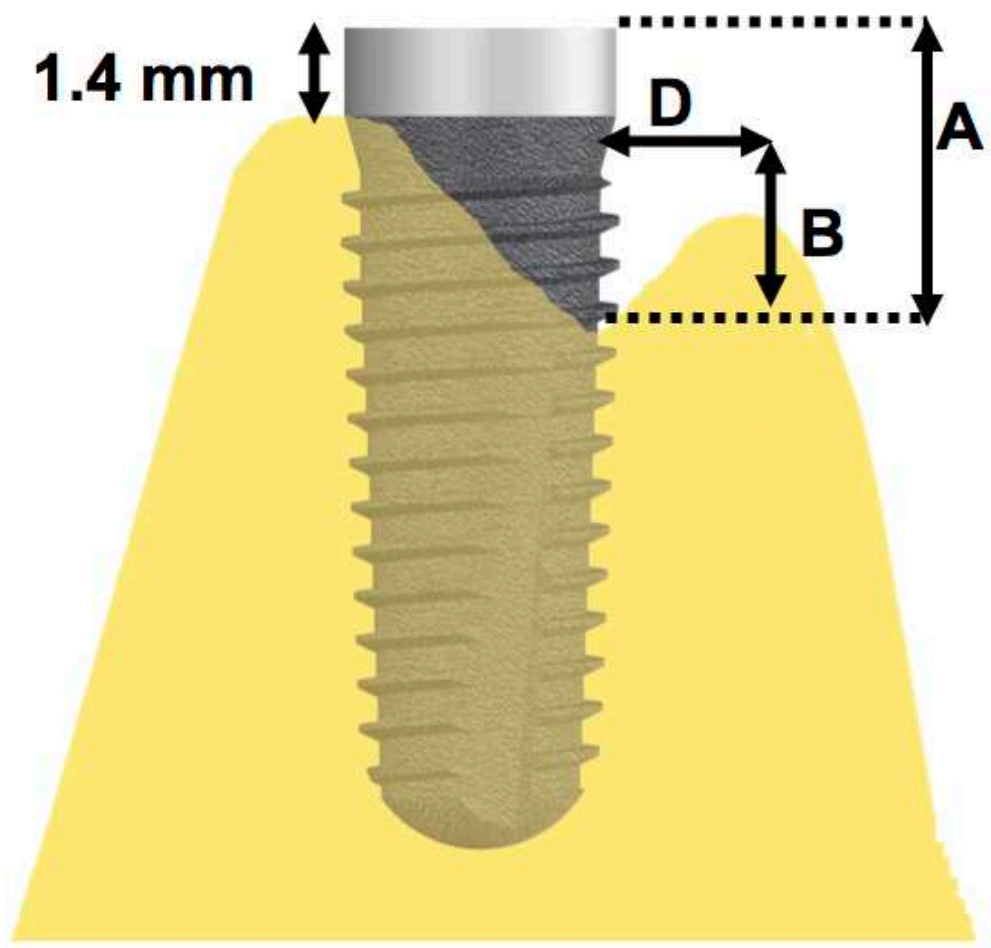

Fig 1b 
Figure 1a,b: Defect dimensions measured at the time of implant placement and after reentry. A: Vertical defect height from implant shoulder to first BIC; B: Infrabony defect height C: Defect width from width from mesial to distal bone crests; D: Defect depth from bone crest to implant surface 


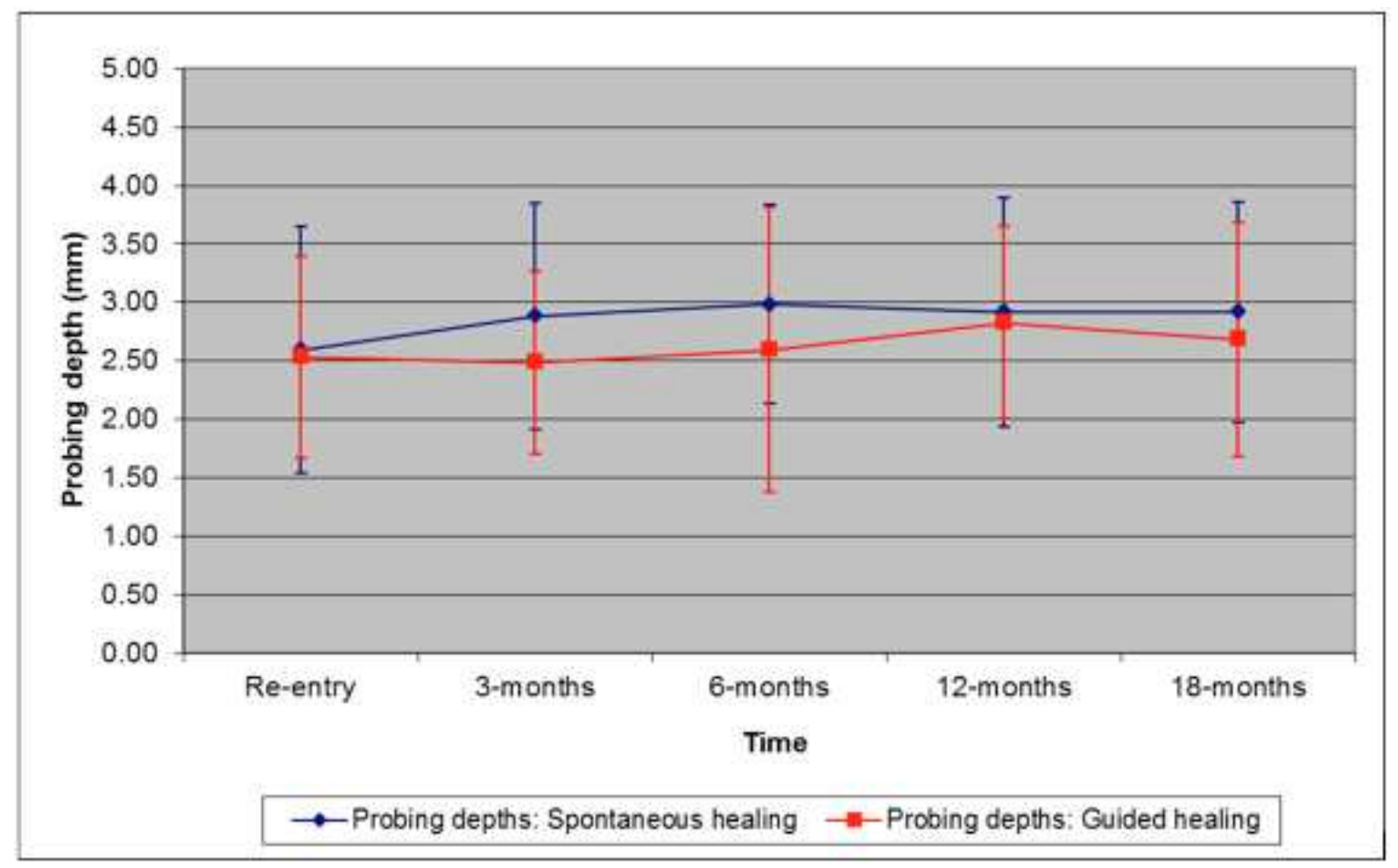

Fig 2 Probing depth: Mean over all measurement sites (mean per implant) including standard deviations

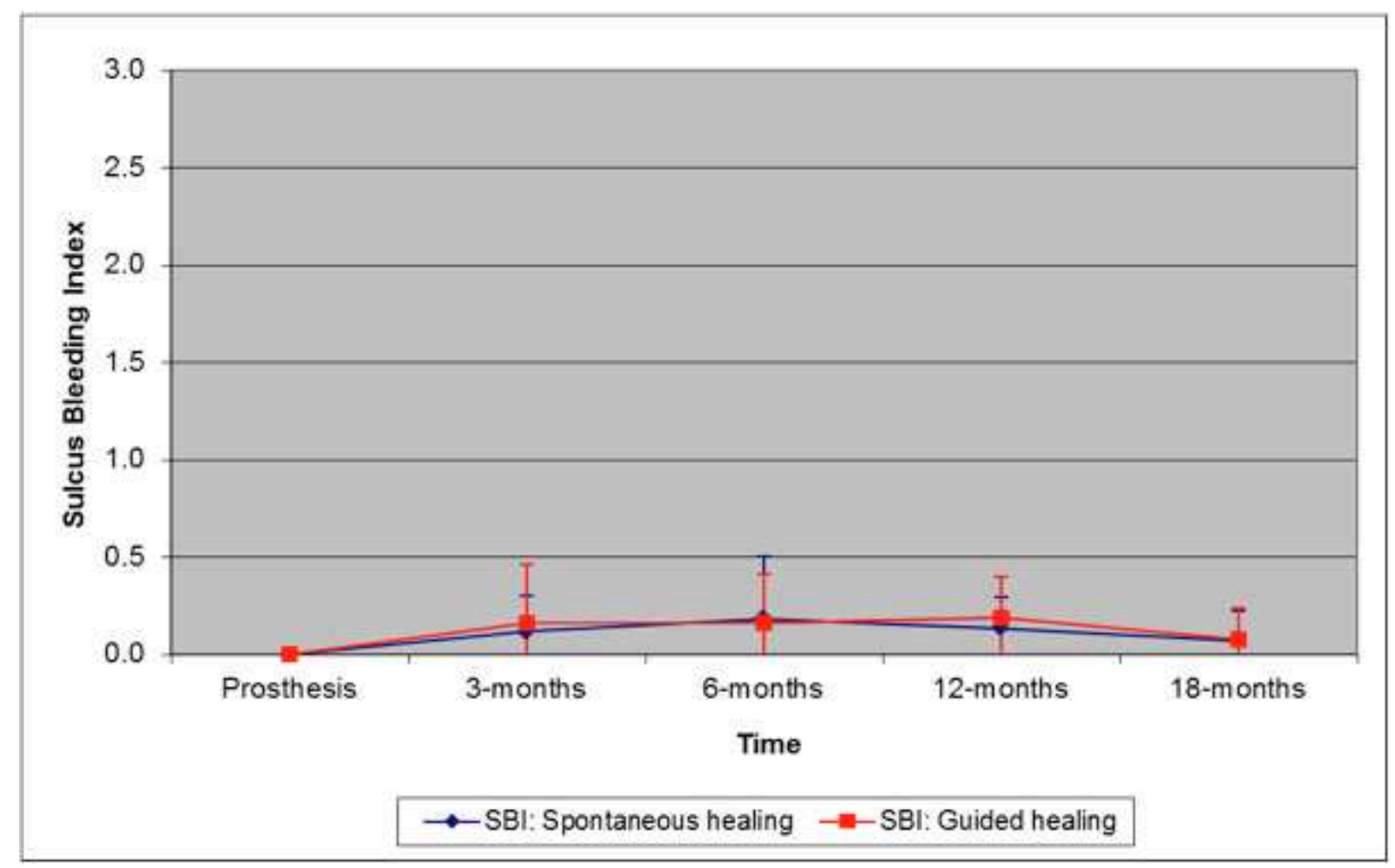

Fig 3 Sulcus bleeding index: Mean over all measurement sites (mean per implant) including standard deviations 


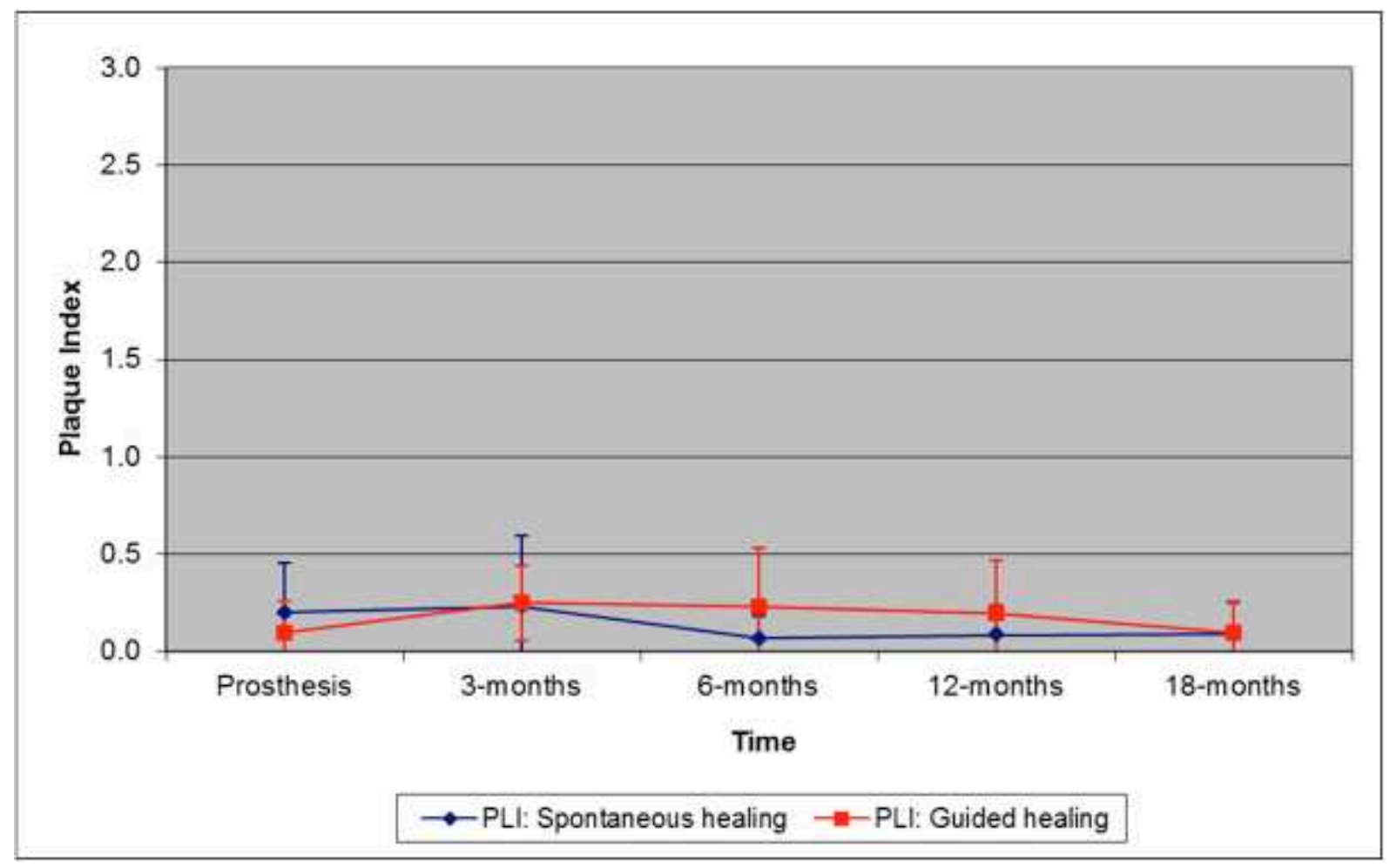

Fig 4 Plaque index: Mean over all measurement sites (mean per implant) including standard deviations 


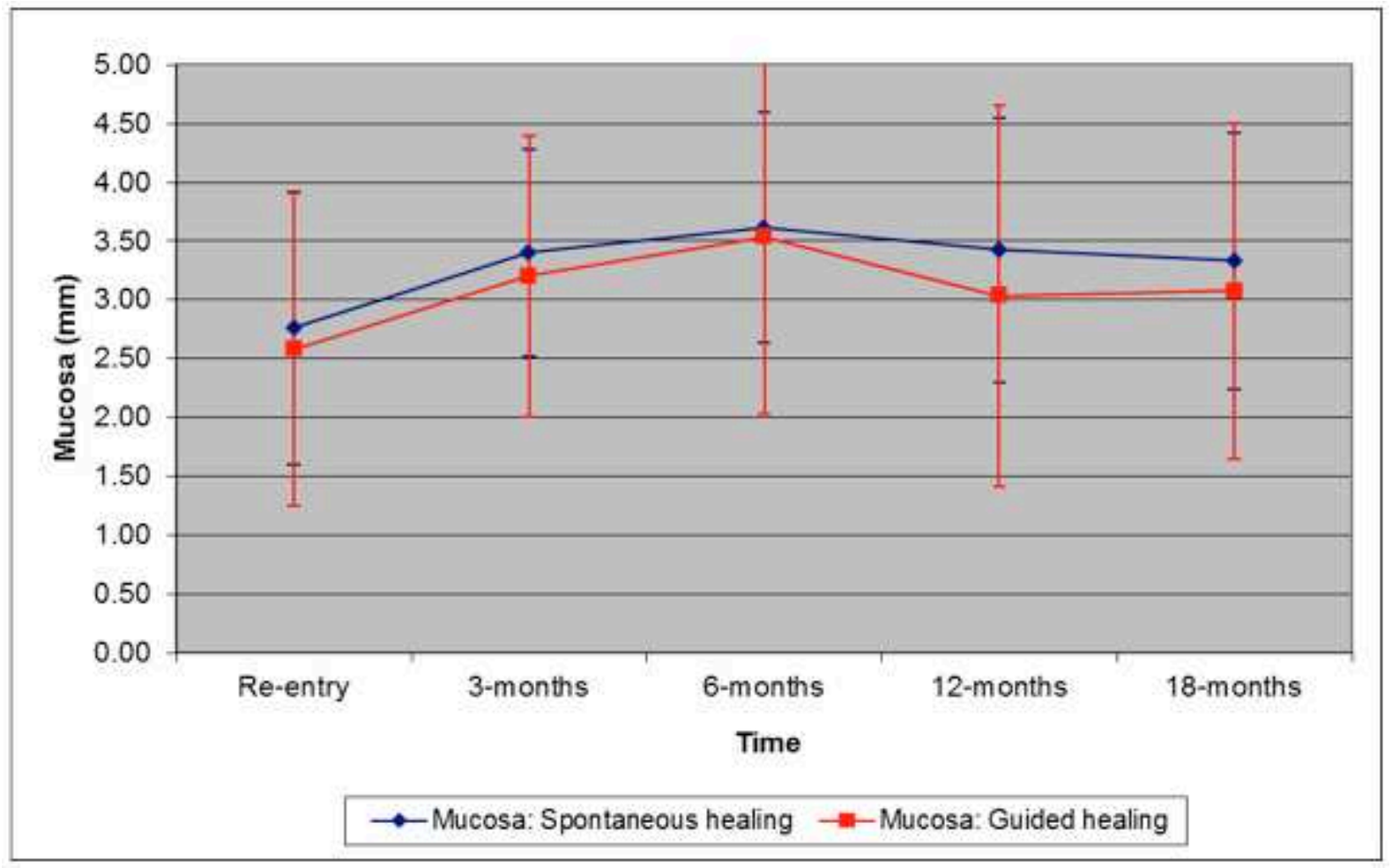

Fig 5 Mucosa level: Mean over all measurement sites (mean per implant) including standard deviations 
Fig. 6 Treatment example from the guided bone regeneration group

6 a initial bone defect at implant placement in position 26

$6 \mathrm{~b}$ bone augmentation with DBBM

$6 \mathrm{c}$ clinical findings at re-entry 6 months after implant placement

$6 \mathrm{~d}$ clinical findings at 18 months follow-up

6 e Radiograph at 18 months follow-up
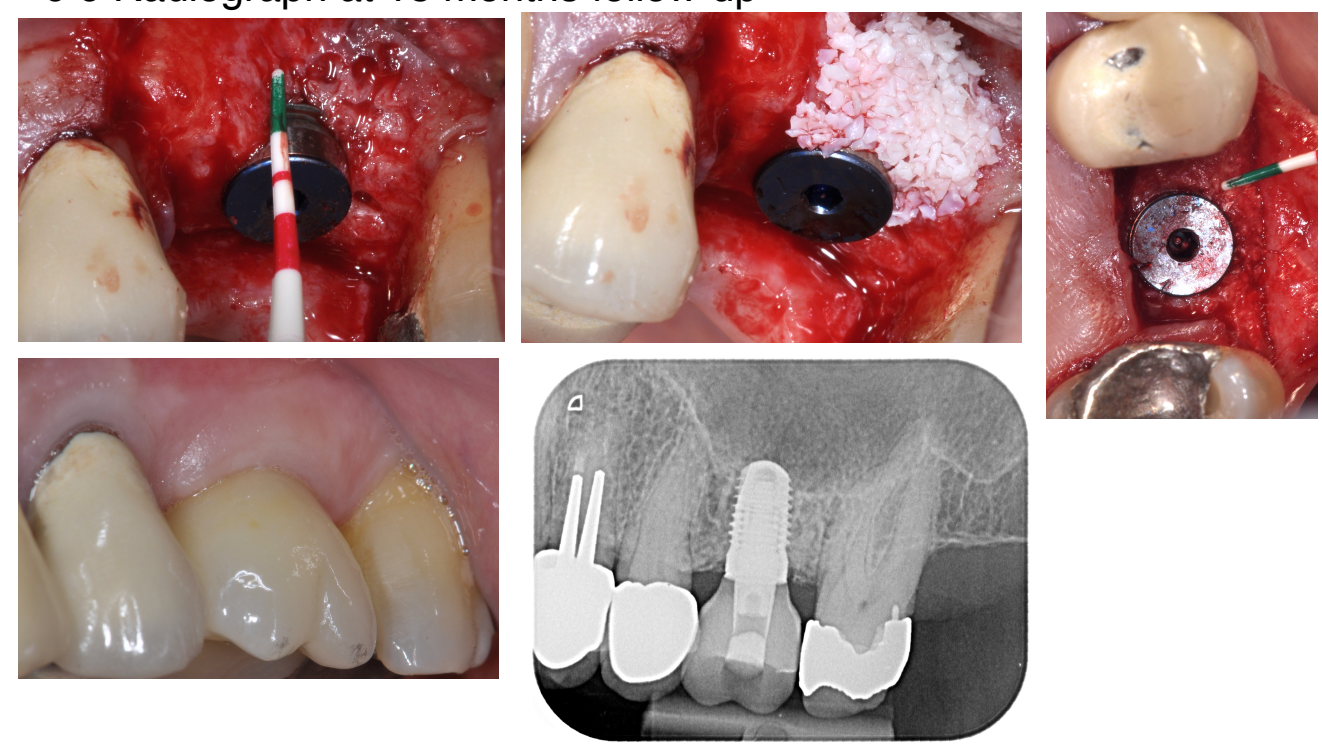
Fig. 7 Treatment example from the spontaneous healing group

7 a initial bone defect at implant placement in position 36

$7 \mathrm{~b}$ clinical findings at re-entry 6 months after implant placement

$7 \mathrm{c}$ clinical findings at 18 months follow-up

7 e Radiograph at 18 months follow-up
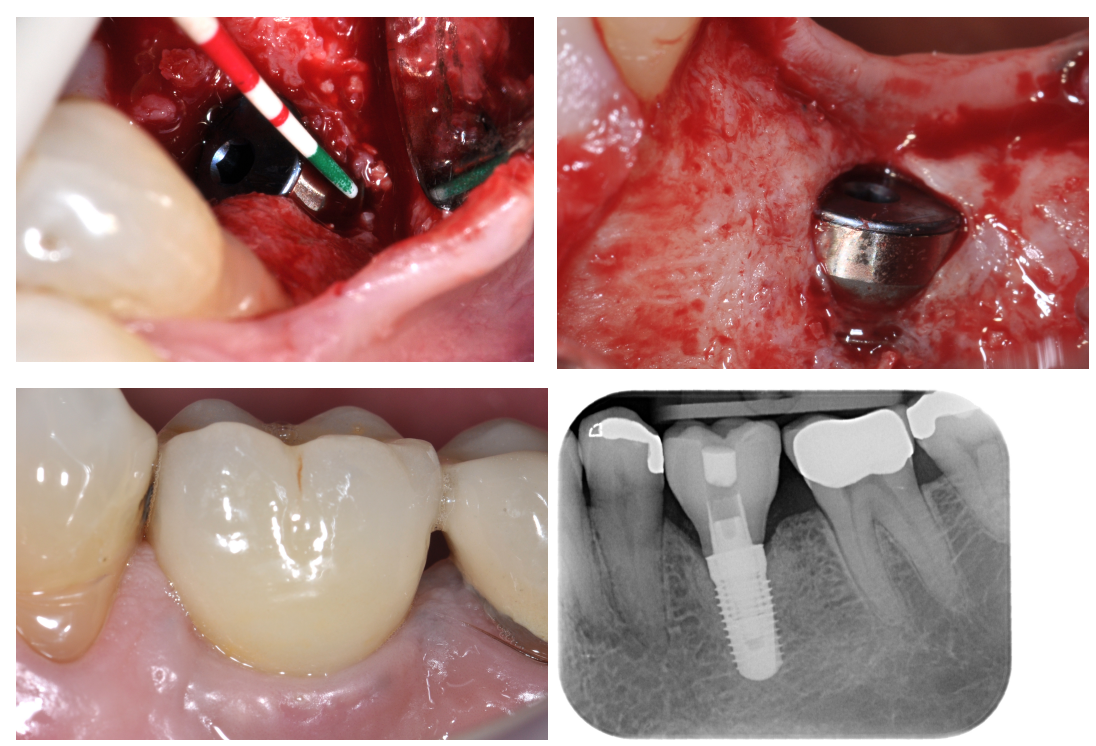


\section{Tables}

\begin{tabular}{|c|c|c|c|c|c|c|}
\hline \multirow{3}{*}{$\begin{array}{l}\text { Implant } \\
\text { position }\end{array}$} & \multicolumn{4}{|c|}{ Treatment randomisation } & & \\
\hline & \multicolumn{2}{|c|}{ Spontaneous healing } & \multicolumn{2}{|c|}{ Guided bone regeneration } & \multicolumn{2}{|c|}{ Total } \\
\hline & Erequency & $\%$ & Erequency & $\%$ & Erequenck & $\%$ \\
\hline 15 & 1 & $6.7 \%$ & 0 & $0.0 \%$ & 1 & $3.6 \%$ \\
\hline 16 & 2 & $13.3 \%$ & 1 & $7.7 \%$ & 3 & $10.7 \%$ \\
\hline 25 & 2 & $13.3 \%$ & 0 & $0.0 \%$ & 2 & $7.1 \%$ \\
\hline 26 & 1 & $6.7 \%$ & 2 & $15.4 \%$ & 3 & $10.7 \%$ \\
\hline 34 & 0 & $0.0 \%$ & 1 & $7.7 \%$ & 1 & $3.6 \%$ \\
\hline 35 & 1 & $6.7 \%$ & 0 & $0.0 \%$ & 1 & $3.6 \%$ \\
\hline 36 & 1 & $6.7 \%$ & 5 & $38.5 \%$ & 6 & $21.4 \%$ \\
\hline 37 & 2 & $13.3 \%$ & 0 & $0.0 \%$ & 2 & $7.1 \%$ \\
\hline 45 & 1 & $6.7 \%$ & 1 & $7.7 \%$ & 2 & $7.1 \%$ \\
\hline 46 & 4 & $26.7 \%$ & 3 & $23.1 \%$ & 7 & $25.0 \%$ \\
\hline Total & 15 & $100.0 \%$ & 13 & $100.0 \%$ & 28 & $100.0 \%$ \\
\hline
\end{tabular}

Table 1: Distribution of the implant positions (FDI classification)

\begin{tabular}{|c|c|c|c|c|c|c|c|}
\hline A_Diff & $\begin{array}{l}\text { Treatment randomisation } \\
\text { Spontaneous healing } \\
\text { Guided bone regeneration }\end{array}$ & $\begin{array}{l}N \\
12 \\
10\end{array}$ & $\begin{array}{c}\text { Minimum } \\
-4 \\
-2.5\end{array}$ & $\begin{array}{c}\text { Maximum } \\
2.5 \\
5\end{array}$ & $\begin{array}{c}\text { Mean }(\mathrm{mm}) \\
-0.17 \\
1.79\end{array}$ & $\begin{array}{c}\text { Std. } \\
\text { Deviation } \\
1.79 \\
2.24\end{array}$ & $\begin{array}{c}\text { Median } \\
0.00 \\
1.75\end{array}$ \\
\hline B_Diff & $\begin{array}{l}\text { Spontaneous healing } \\
\text { Guided bone regeneration }\end{array}$ & $\begin{array}{l}12 \\
10\end{array}$ & $\begin{array}{c}-0.5 \\
0\end{array}$ & $\begin{array}{l}2.5 \\
2.5\end{array}$ & $\begin{array}{l}0.29 \\
0.60\end{array}$ & $\begin{array}{l}0.78 \\
0.84\end{array}$ & $\begin{array}{l}0.00 \\
0.25\end{array}$ \\
\hline C_Diff & $\begin{array}{l}\text { Spontaneous healing } \\
\text { Guided bone regeneration }\end{array}$ & $\begin{array}{l}12 \\
10\end{array}$ & $\begin{array}{c}-2.5 \\
-1\end{array}$ & $\begin{array}{l}5 \\
5\end{array}$ & $\begin{array}{l}0.38 \\
1.25\end{array}$ & $\begin{array}{l}1.84 \\
1.84\end{array}$ & $\begin{array}{l}0.00 \\
0.75\end{array}$ \\
\hline D_Diff & $\begin{array}{l}\text { Spontaneous healing } \\
\text { Guided bone regeneration }\end{array}$ & $\begin{array}{l}12 \\
10\end{array}$ & $\begin{array}{c}-0.5 \\
0\end{array}$ & $\begin{array}{l}2 \\
2\end{array}$ & $\begin{array}{l}0.21 \\
0.40\end{array}$ & $\begin{array}{l}0.69 \\
0.66\end{array}$ & $\begin{array}{l}0.00 \\
0.00\end{array}$ \\
\hline
\end{tabular}

Table 2: Bone changes from implant insertion to the reentry after 6 months (A_Diff, B_Diff, C_Diff, D_Diff; negative value = bone loss; positive value = bone gain), one implant selected per patient 